\title{
The Residual Stress Effect on the Shape Memory Polymers
}

\author{
A. Kallel ${ }^{1, a^{*}}$, M. Lamraoui ${ }^{2, b}$, J. Fitoussi ${ }^{2, c}, A$. Tcharkhtchi $^{2, d}$, \\ ${ }^{1}$ Léonard de Vinci Pôle universitaire, Research center, Paris la Défense, France \\ ${ }^{2}$ Laboratoire PIMM, UMR 8006 CNRS, Arts et Métiers ParisTech, Paris 75013, France \\ aachraf.kallel@devinci.fr, ${ }^{b}$ menad.lamraoui@ensam.eu, ${ }^{\circ}$ joseph.fitoussi@ensam.eu, \\ dabbas.tcharkhtchi@ensam.eu
}

\begin{abstract}
Keywords: Shape Memory Polymers, Residual Stress Effect, Driving Force, Blend PCL ISBS
\end{abstract}

\begin{abstract}
The current paper presents an experimental study of the residual stress role to recover polymer blend to its original position after deformation. In this study, we use a polymer blend of 40\% PolyCaproLactone (PCL) and 60\% Styrene-Butadiene-Styrene (SBS). The Shape Memory Polymer (SMP) is able to storing a permanent macroscopic after passing through a temporary one; then under an external stimulus; they can recover their initial shapes. The recovery rate depends on the mechanical property of the mixture and also of the number of the loading cycles. Indeed, one multiplying the number of mechanical loading cycle; generally tensile test; the recovery rate does not change in a linear manner and therefore the residual stress is not added in integer from one cycle to another. In this work we studied the mechanism of the shape as well as property memory effect of the blend under study during a shape memory cycle, to establish a relationship between the "shape memory effect" and the "properties memory effect". Finally, we measure the "Driving Force" responsible for the shape memory effect by an original method. This study allows establishing a relationship between the rate of recovery and residual stresses introduced into the polymer during its deformation.
\end{abstract}

\section{Introduction}

Shape memory polymers (SMPs) have the capacity of changing their shapes from a temporary shape to a permanent shape upon an external stimulus. The stimulus could be provided by thermal $[1,2]$, magnetic or electric sources [3]. In the case of thermal stimulus, the cycle process consists of first a deformation at high temperature, relaxation, fixing and finally recovery [4-6]. SMPs are useful in many domains as medical and biological devices [8,9], smart textile $[10,11]$, tubing and actuating materials and packaging components [12-14]. The capacity of SMPs to change shape is generally explained by the presence of at least two different phases with different mechanical properties (hard and soft). Recently different new concepts regarding to certain aspects related to shape memory effect were shown [4-6]. We can consider as concept the Property Memory Effect (PME) in which stress-strain tensile tests and both mono and multi-frequency DMA (Dynamic Mechanical Analyzer) tests on virgin and $100 \%$ recovered samples of PU (rubber) revealed that the polymer at the end of the shape memory tests regains $100 \%$ of its initial form without regaining some of its physical properties like the glass transition temperature, the tensile modulus, the heat expansion coefficient and the free volume fraction. After recovery tests on a stretched sample, the majority of the polymers regain only a certain percentage of their initial shape. The Degree of Shape Memory Effect (DSME) is defined as the percentage of the residual shape. This denotes the Partial Shape Memory Effect (PSME) concept. The successive cyclic tensile tests on partial shape memory polymers (PSMP) show that the DSME increases with the increase of the number of cycles. This test also showed the shape capacity of polymer increases by the number of cycles. This new concept of shape memory effect is 
of very important value. We can in a legitimate way suppose that a polymer without shape memory effect can be transformed into a shape memory polymer.

Another new concept concerns the driving force responsible of recovery phenomenon. It has been shown that during shape memory cycling tests, and during fixing test the polymer is cooled down rapidly in order to fix the shape obtained at the end of the test. In this period the residual stresses will be locked in the structure. This residual stress is indeed the origin of driving force responsible for the shape memory effect [4-6]. During recovery, at a temperature higher than the glass transition of soft segments, these stresses are released and the SMP regains its initial shape.

In the present work, in order to study the origin of this driving force "Driving force", the relationship between the recovery rate and the residual stresses, introduced into the polymer during its deformation, has been determined.

\section{Experimental}

Materials. A mixture of polycaprolactone (PCL) (40\%) and Styrene-Butadiene-Styrene (SBS) $(60 \%)$ is used. This blend shows almost a total shape memory effect. We choose this percentage because it gives a good combination of shape recovery ratio and shape fixing ratio [18]. The PCL that was used for this study is PCL CAPA 860 supplied by Perstrop Limited UK with a density of $1.14 \mathrm{~g} / \mathrm{cm}^{3}$ of density and its $\mathrm{Tg}$ and $\mathrm{Tm}$ are respectively $-50^{\circ} \mathrm{C}$ and $60^{\circ} \mathrm{C}$. The used StyreneButadiene-Styrene (SBS); provided by the company Sinopec Group, is an amorphous copolymer (Tg $=-80^{\circ} \mathrm{C}$ ) between the polybutadiene rubber $(\mathrm{PB})$ and thermoplastic polystyrene (PS).

Determinations of melting point and glass transition temperature. A TA instruments DSCQ10 V9.0 Build 275 type Differential Scanning Calorimetry has been used to determine the transition temperature of polymers. Specimens have been cooled with nitrogen from room temperature to -80 ${ }^{\circ} \mathrm{C}$ (Minimal temperature that the machine can achieve) and then heated until $80{ }^{\circ} \mathrm{C}$ at a constant rate of $3{ }^{\circ} \mathrm{C} / \mathrm{min}$.

Pure PCL presents a melting point of $59,2{ }^{\circ} \mathrm{C}$ [18]. Pure SBS is an amorphous polymer without any melting point. The blend shows a melting point of $57,6{ }^{\circ} \mathrm{C}$ which is almost the same as the pure PCL (Fig. 1). In order to determine the glass transition temperature, dynamical mechanical thermal analysis (DMTA) tests has been carried out using a DMA Q800 TA Instruments. A $1 \mathrm{~Hz}$ frequency has been performed between $-100^{\circ} \mathrm{C}$ to $0^{\circ} \mathrm{C}$ with a heating rate of $3^{\circ} \mathrm{C} / \mathrm{min}$,

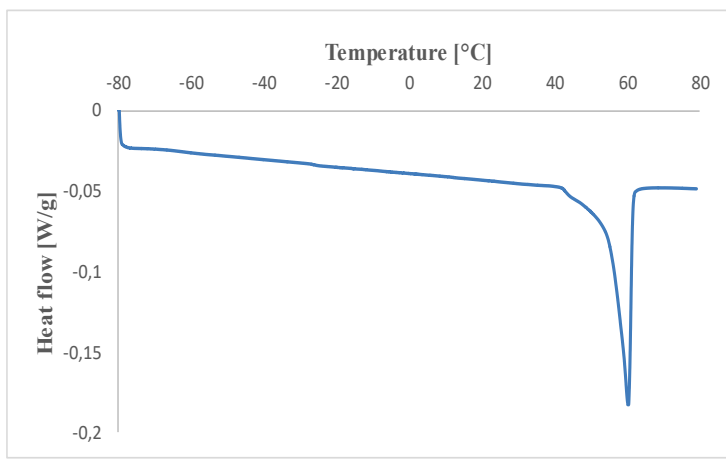

Fig. 1: DSC Results of: (a) pure PCL, (b) pure SBS and (c) PCL (40\%) /SBS (60\%) blend.

These curves in Fig. 2 show that the transition temperature of the SBS and PCL are $-82^{\circ} \mathrm{C}$ and $42^{\circ} \mathrm{C}$, respectively. These results reinforce the fact that the SBS and the PCL are not miscible because their Tg remain the same in the blend. Fig. 3 showed the MEB images of a virgin simple (right image) and a simple after one SM cycle (left image). The bright region was PCL phase and the dark region was SBS phase. That shows the intrinsic immiscibility between the SBS, the soft phase, and the PCL the hard phase. This confirms DMA results showing two different transition temperatures: the lowest corresponds to the soft phase (SBS) and the highest corresponds to the hard phase (PCL). 

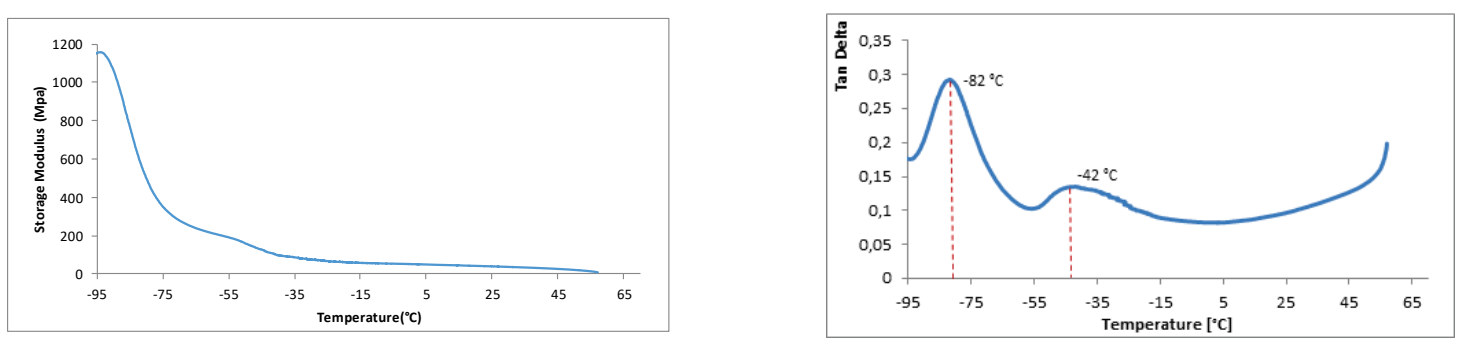

Fig. 2: DMTA analysis of virgin sample
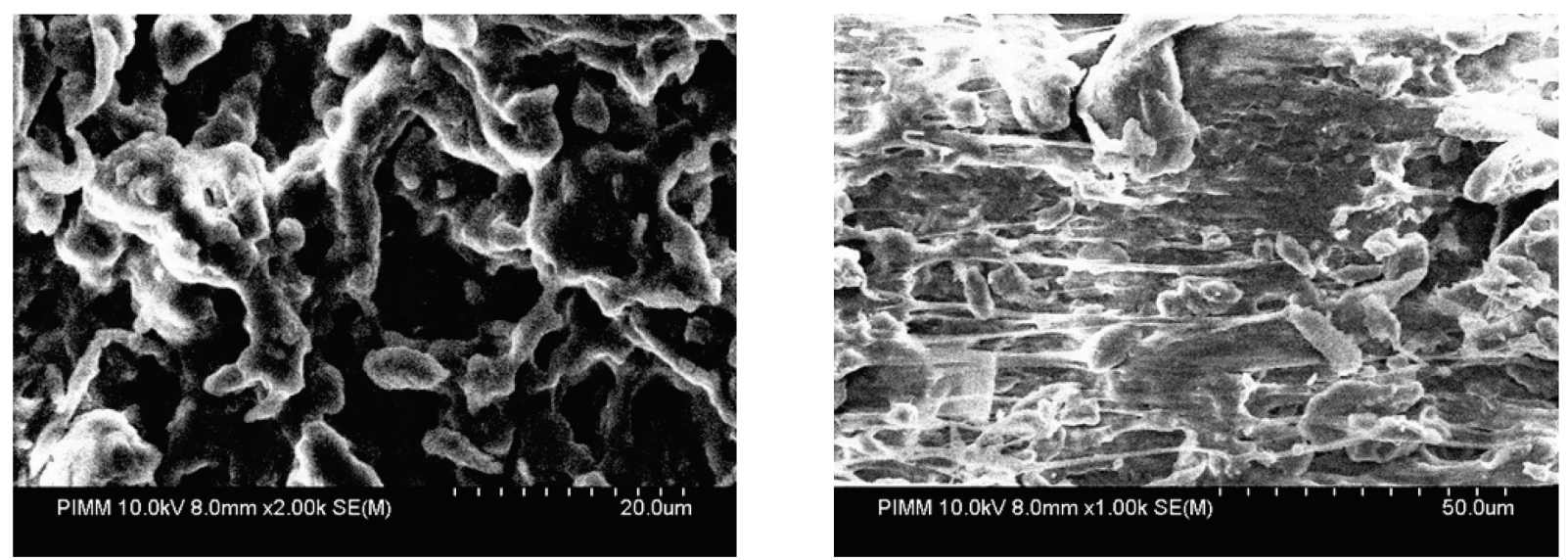

Fig. 3: The MEB images of the cross-section of the blend SBS $60 \%$ and PCL $40 \%$.

Tensile and shape memory test. The stress-strain tests have been done by a uniaxial-tensile loading Instron 5566-type machine with a load cell of $1 \mathrm{kN}$ at room temperature, according to the standard NF ISO 6239 [17].

Shape memory test was carried according to the following steps: (1) heating the sample up to $50^{\circ} \mathrm{C}$ and holding for 10 minutes; (2) extending to the strain of $100 \%$ with a speed of $6 \mathrm{~mm} / \mathrm{min}$ (tensile test) (3) fixing this deformation by cooling down the sample to the room temperature using a fan for $10 \mathrm{~min}$ (4) unloading the sample to zero stress and then recording the strain (5) heating up the sample to above the glass transition temperature of the blend and then recording the strain (recovery test). During this step, the length of the sample decreases and thanks to the shape memory effect, the sample recovers all its substantial original shape. It is important to indicate that the recovery test cannot practically be performed isothermally because during heating, the oven from room temperature up to $50^{\circ} \mathrm{C}$ and before reaching this temperature, the sample begins its deformation for recovering its initial shape. So recovery test was carried out in ramp (constant temperature rate) condition.

For multi-cycle tests, successive shape memory cycles were performed on the same sample. At the end of the first recovery cycle test, the sample is subjected to another shape memory cycle, i.e. tensile, fixing and recovery. This cycle was repeated a several times.

\section{Results and discussion}

Thermal effects on the mechanical and the shape memory properties. The results of tensile tests on the SBS/PCL blend are shown in Figure 5 and table 2. These results clearly show the influence of temperature on mechanical properties. The stress decreases with increasing temperature. We can note that the thresholds which separate elastic and plastic areas are at $8 \%$ of strain $(\varepsilon)$. The strain energy can be stored in the polymer structure, which subsequently will be released under the effect of thermal stimulation. This stored energy is the source of the driving force that will bring the sample to its original shape. 


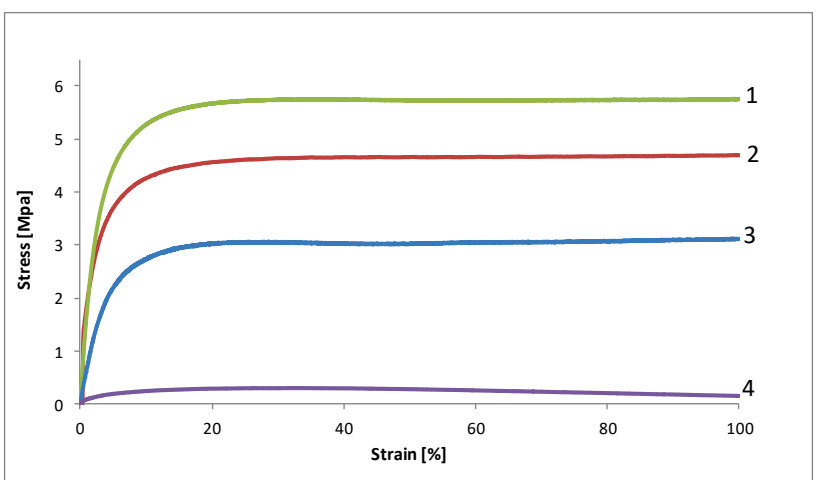

Table 1: Young modulus values and stress at $100 \%$ of strain at different temperature

\begin{tabular}{|c|c|c|}
\hline $\mathrm{T}\left({ }^{\circ} \mathrm{C}\right)$ & $\begin{array}{c}\text { Modulus } \\
{[\mathrm{MPa}]}\end{array}$ & $\begin{array}{c}\text { Stress at } 100 \% \\
\text { strain [MPa] }\end{array}$ \\
\hline 25 & 174 & 5.7 \\
\hline 35 & 103 & 4.7 \\
\hline 50 & 66 & 3.1 \\
\hline 60 & 7 & 0.3 \\
\hline
\end{tabular}

Fig. 5: Tensile tests of SBS / PCL blend at different temperatures: (1) $25^{\circ} \mathrm{C}$, (2) $35^{\circ} \mathrm{C}$, (3) $50^{\circ} \mathrm{C}$, (4) $60^{\circ} \mathrm{C}$

Fig. 5 shows that the blend is less rigid at high temperature. The curve's initial slope (Young Modulus) as well as the sample's stiffness is inversely proportional to the temperature. $50^{\circ} \mathrm{C}$ will be used as a reference temperature for the entire tensile test. The recovery test is carried out in a thermal chamber for a range of temperature after holding at $100 \%$ of deformation. The recovery rate and the fixing rate are respectively:

$$
R_{r}(\%)=\frac{L_{u}-L_{f}}{L_{u}-L_{i}} * 100 \quad(1), \text { and } R_{f}(\%)=\frac{L_{u}}{L_{m}} * 100
$$

Where $L_{i}$ is the initial sample length, $L_{m}$ the length after $100 \%$ of deformation, $L_{u}$ the length after tensile test without stress (jaws are release) and $L_{f}$ is the t length after recovery.

To calculate the recovery rate, w used $L_{u}$, the length after tensile te: without stress, and not $L_{m}$, the lengt after $100 \%$ of deformation, becaus when we release the jaws th sample's length changes. The fixin rate is not equal to $100 \%$.

Table 2: Recovery tests at different temperature

\begin{tabular}{|c|c|c|}
\hline Temperature $\left[{ }^{\circ} \mathrm{C}\right]$ & $\operatorname{Rr}[\%]$ & $\operatorname{Rf}[\%]$ \\
\hline 75 & 97,2 & 92,9 \\
\hline 65 & 91,1 & 94,1 \\
\hline 55 & 71,9 & 93,4 \\
\hline
\end{tabular}

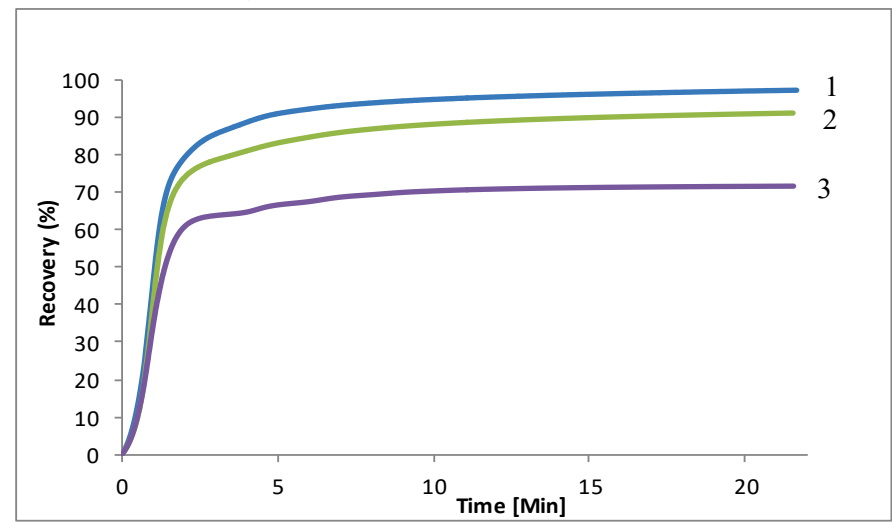

Fig. 6: Recovery rate at different temperature: (1) $75^{\circ} \mathrm{C}$, (2) $65^{\circ} \mathrm{C}$, (3) $55^{\circ} \mathrm{C}$

Molecular mobility increases by rising the temperature. For our blend, $100 \%$ recovery is reached in about $20 \mathrm{~min}$ with $75{ }^{\circ} \mathrm{C}$ while for $55^{\circ} \mathrm{C}$ the polymer reached only $71,9 \%$ of recovery. For this blend, the SBS chains, the soft phase, ensure the recovery.

Multi-cycle effects on mechanical and shape memory properties. Multi-cycle tests were performed to study their effects on the mechanical and shape memory properties. For these assessments, we will use $50^{\circ} \mathrm{C}$ for tensile test and $55^{\circ} \mathrm{C}$ for recovery test.

The residual stress stored in the sample after each tensile test, need a thermal stimulus to be released. The amount of the internal energy stored during the cycle is more important when the tensile test is made at $-30^{\circ} \mathrm{C}$ than at $23^{\circ} \mathrm{C}$. Therefore, for sample which the tensile test is made at $30^{\circ} \mathrm{C}$, the recovery starts at low temperature and can reach $55 \%$ at the ambient temperature. 


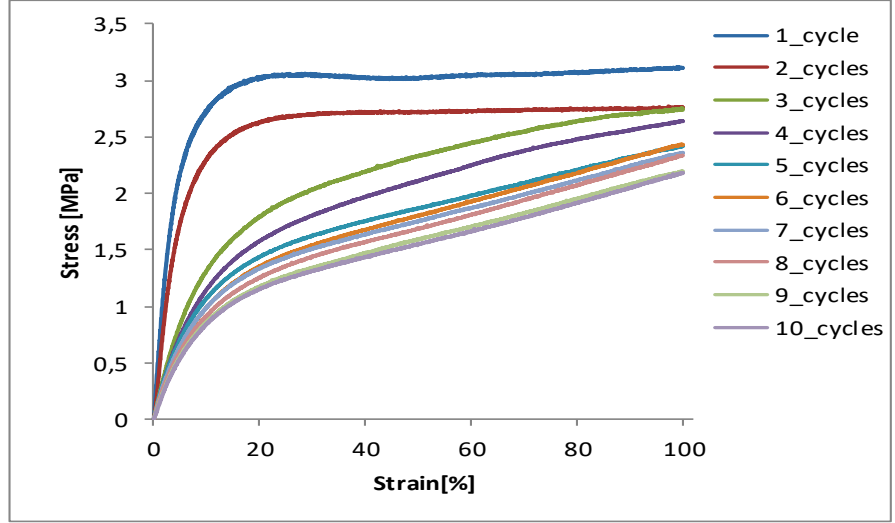

Fig. 7: Tensile test for different cycles

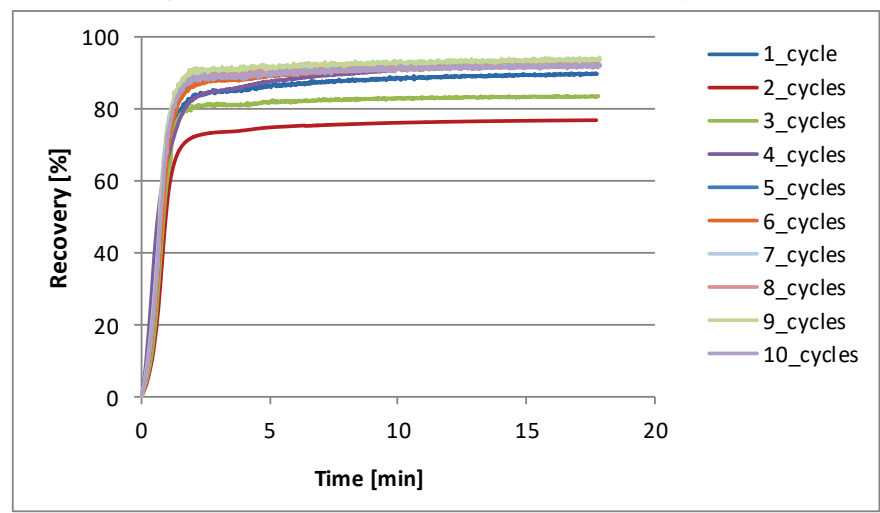

Fig. 8: Recovery rate for different cycles.

Tensile tests were carried out on a sample after shape memory cycles. Results are given in figure 8 . We can notice that the specimen's stress decreases from $3.1 \mathrm{Mpa}$ (cycle1) to $2.1 \mathrm{Mpa}$ after 10 shape memory cycles. The Young modulus undergoes a significant decrease because it passes from 65.6 Mpa in the first cycle to $12.1 \mathrm{Mpa}$ in the tenth cycle.
Table 3: Maximal stress and Modulus for each cycle

\begin{tabular}{|c|c|c|}
\hline $\begin{array}{c}\text { Strain } \\
\text { cycles }\end{array}$ & $\begin{array}{c}\text { Stress } \\
{[\mathrm{MPa}]}\end{array}$ & $\begin{array}{c}\text { Modulus } \\
{[\mathrm{MPa}]}\end{array}$ \\
\hline 1 & 3,1 & 65,6 \\
\hline 2 & 2,7 & 46,8 \\
\hline 3 & 2,7 & 20,5 \\
\hline 4 & 2,6 & 17,6 \\
\hline 5 & 2,4 & 17,6 \\
\hline 6 & 2,4 & 15,2 \\
\hline 7 & 2,3 & 14,9 \\
\hline 8 & 2,3 & 13,7 \\
\hline 9 & 2,1 & 12,3 \\
\hline 10 & 2,1 & 12,1 \\
\hline
\end{tabular}

Table 4: Fixing rate and Recovery rate at different cycles

\begin{tabular}{|c|c|c|}
\hline Cycles & $\operatorname{Rr}[\%]$ & $\operatorname{Rf}[\%]$ \\
\hline 1 & 89,7 & 94,6 \\
\hline 2 & 76,9 & 94 \\
\hline 3 & 83,5 & 93,7 \\
\hline 4 & 90,7 & 92,2 \\
\hline 5 & 92,2 & 88,8 \\
\hline 6 & 92 & 89,1 \\
\hline 7 & 92,4 & 88,1 \\
\hline 8 & 93,1 & 87,8 \\
\hline 9 & 93,7 & 87,7 \\
\hline 10 & 92 & 88,1 \\
\hline
\end{tabular}

\section{Conclusion}

After a shape memory cycle; the soft material, more sensitive to the deformation, is going to store some strain energy which will be afterward a source for the driving force to return to the initial shape. Whereas the hard phase, during the tensile test, resist to the deformation of the soft chains and this resistance is going to create residual stress in the hard phase which will be released by an external stimulus (heating). The direct measure of the residual stress by diffraction for our example will be very difficult to see impossible because the mixture is not crystalline and does not present any arrays as the case of the steel or other metals. We remark that the blend regains $90 \%$ of its initial shape after the first memory test and that the recovery rate varies in a random way until the fifth cycle from which it stabilizes around $92 \%$ until tenth cycles. The fixing rate decrease from $94 \%$ in the first cycle to $88 \%$ in the fifth one. Then it keeps this rate until the tenth cycle. We can notice that even when the sample regains almost its initial shape after each cycle, it does not have the same mechanicals properties. We can notice that the sample does not remain the same viscoelastic properties even when it regains almost its initial shape after each cycle. 


\section{References}

[1] Lendlein A, Kelch S. Shape-memory polymers. Angew Chem Int Ed 2002;41:2034-57. http://dx.doi.org/10.1002/1521-3773(20020617)41:12<2034::AID-ANIE2034>3.0.CO;2-M

[2] Behl M, Lendlein A. Shape-memory polymers. Materials Today 2007;10:20-8. http://dx.doi.org/10.1016/S1369-7021(07)70047-0

[3] Leng J, Lu H, Liu Y, Du S. Conductive nanoparticles in electro activated shape memory polymer sensor and actuator. Paper presented at the proceedings of SPIE - the international society for optical engineering. Nanosensors and microsensors for bio-systems, San Diego, CA, United States, vol. 6931; 2008. p. 693109. http://dx.doi.org/10.1117/12.775743

[4] Tcharkhtchi A. and al, Some New Concepts of Shape Memory Effect of Polymers. Polymers 2014, 6, 1144-1163. http://dx.doi.org/10.3390/polym6041144

[5] Farzaneh, S., Fitoussi, J., Lucas, A., Bocquet, M., Tcharkhtchi, A., "Shape memory effect and properties memory effect of polyurethane", Journal of Applied Polymer Science, Volume 128, Issue 5, pages 3240-3249, 2013. http://dx.doi.org/10.1002/app.38530

[6] S. Abdallah-Elhirtsi, J. Fitoussi, B. J. Rashmi, K. Prashantha, S. Farzaneh, M. F. Lacrampe, P. Krawczak, A.Tcharkhtchi, "Study of partial shape memory effect of polymers by multicycle tests", , Polymer Composites, 36 (6), pp. 1145-1151 (2015). http://dx.doi.org/10.1002/pc.23472

[7] T. Tadaki and al. Shape Memory Alloys. Annual Review of Materials Science. Vol. 18: 25-45 (1988). http://dx.doi.org/10.1146/annurev.ms.18.080188.000325

[8] Lendlein A, Langer R. Biodegradable, elastic shape-memory polymers for potential biomedical applications. Science 2002;96:1673-6. http://dx.doi.org/10.1126/science.1066102

[9] Wache HM, Tartakowska DJ, Hentrich A, Wagner MH. Development of a polymer stent with shape memory effect as a drug delivery system. J Mat. Sci: Mater Med 2004;14:109-12. http://dx.doi.org/10.1023/A:1022007510352

[10] Hu JL, Ding XM, Tao XM. Shape memory polymers and their applications to smart textile products. J China Textile Univ 2002;19:89-93. Application textile

[11] Russel DA, Hayashi S, Yamada T. The potential use of memory film in clothing. Paper presented at the techtextil symposium-new protective textiles (through textile technology index database), April 1999. Application textile

[12] J. Karger-Kocsis. Recent advances in shape memory polymers and composites: a review. J Mater Sci (2008) 43:254-269. http://dx.doi.org/10.1007/s10853-007-2176-7

[13] T. Xie. Recent advances in polymer shape memory. Polymer 52 (2011) 4985-5000. http://dx.doi.org/10.1016/j.polymer.2011.08.003

[14] J. Hu. Recent advances in shape-memory polymers: Structure, mechanism, functionality, modeling and applications. Progress in Polymer Science 37 (2012) 1720- 1763. http://dx.doi.org/10.1016/j.progpolymsci.2012.06.001

[15] Lin JR, Chen LW. Study on shape-memory behavior of polyether-based polyurethanes. I. Influence of the hard-segment content. J Appl Polym Sci 1998;69:1563-74. http://dx.doi.org/10.1002/(SICI)1097-4628(19980822)69:8<1563::AID-APP11>3.0.CO;2-W

[16] Lin JR, Chen LW. Study on shape-memory behavior of polyether-based polyurethanes. II. Influence of soft-segment molecular weight. J Appl Polym Sci 1998;69:1575-86. http://dx.doi.org/10.1002/(SICI)1097-4628(19980822)69:8<1575::AID-APP12>3.0.CO;2-U

[17] NF ISO 6239:1986. Plastics Determination of Tensile Properties by Use of Small Specimens. Association Française de Normalisation (AFNOR): Seine-Saint-Denis, France, 1986.

[18] Zhang H., Wang H., Zhong W. and Du Q. A novel type of shape memory polymer blend and the shape memory mechanism. Polymer $50 \quad$ (2009) 1596-1601. http://dx.doi.org/10.1016/j.polymer.2009.01.011 